\title{
Study on Water Quality Monitoring of Daihai Lake Based on Remote Sensing Technology
}

\author{
Xiuqing Wu ${ }^{1}$, Changbao Yang ${ }^{2}$, Yaowen Chang ${ }^{3}$, Qian Duan ${ }^{4}$ \\ 1, 3,4 Department of Environmental Engineering, Hohhot Miinzu College, Hohhot, China, 010051 \\ ${ }^{2}$ School of Ethnology and Sociology, Inner Mongolia University, Hohhot, China, 010021
}

Keywords: remote sensing technology; Daihai lake; chlorophyll; total nitrogen; total phosphorus

\begin{abstract}
In this study, Daihai lake is used as the experimental area, and the method and technology of monitoring water quality in the lake area with remote sensing data are applied. Through the integration of envi software and ArcGIS software, the Landsat - 5 image data on September 1, 2008 and Landsat - 8 image data on November 4, 2017 are used to evaluate the concentration of chlorophyll, total nitrogen and total phosphorus in Daihai lake.

The research purpose of this paper is to explore a method model that can use remote sensing technology to monitor the water quality of inland water bodies by carrying out remote sensing monitoring methods and technology research on eutrophication of inland water bodies.
\end{abstract}

\section{Introduction}

The emergence and development of remote sensing technology in the 20th century opened up a new way for monitoring and studying water quality. Using remote sensing technology to monitor lake water body has the advantages of strong timeliness, wide monitoring range, low cost and so on. Therefore, it has become a hot research topic in remote sensing and environmental protection circles at home and abroad to use remote sensing technology to carry out water quality monitoring research, invert the concentration of various water quality parameters in the lake water body, obtain the overall water quality distribution in the lake region, and then put forward corresponding control measures to prevent and reduce further pollution of the lake water quality.

Abroad, remote sensing technology has been used in inland water quality evaluation since 1970s. Remote sensing water quality monitoring method experienced the development process of analysis method in 1980s, experience method in 1990s and semi-experience method after 1990s. At the same time, the remote sensing data source used for water quality monitoring has also developed from the original MSS data with low resolution and wide band to the current remote sensing image data source with high spatial and high spectral resolution. Compared with foreign countries, the domestic research and development place is relatively late and began in the early 1990s.

\section{Survey of Research Area}

Daihai lake is located in Liangcheng county, Wulanchabu city, inner Mongolia. it is one of 365 lakes with good water quality listed and protected by the state. it is about 25 kilometers long from east to west, about 20 kilometers wide from north to south, and 61.56 kilometers long along the lake coastline. the common lake area is 160 square kilometers, with a maximum depth of 15.00 meters and a volume of 989 million cubic meters. its water source is formed by the accumulation of more than 20 rivers and middle-level groundwater around it.

According to xinhuanet.com, the shrinking trend of Daihai lake, the third largest inland lake in inner Mongolia, slowed down. the area of the lake decreased from 3.9 square kilometers per year before 2016 to 2 square kilometers. the water level decreased to 0.3 meters from 0.61 meters in 2015. some major water quality indicators such as potassium permanganate and ammonia nitrogen also improved. In recent years, due to reduced precipitation and over-exploitation of water resources, the water surface of Daihai lake has shrunk sharply, the water level has plummeted and 
the water quality has deteriorated (the shrinking momentum of Daihai lake, the third largest inland lake in inner Mongolia, has slowed down, xinhuanet, 2018 - 03 - 12, http: / / news.iqilu.com / China / gedi / 2018 / 0312 / 3857608.shtml).

In order to confirm the water quality dynamics of Daihai lake, this study used remote sensing technology to evaluate the water quality index concentrations of chlorophyll, total nitrogen and total phosphorus in Daihai lake on September 1, 2008 and November 4, 2017.

\section{Remote Sensing Technology and Introduction of Remote Sensing Image Data}

\subsection{Introduction of remote sensing technology}

Remote sensing refers to non-contact and long-distance detection technology. Generally, refers to the use of sensors / remote sensors to detect the radiation and reflection characteristics of electromagnetic waves of objects. A science and technology that obtains electromagnetic wave information (such as electric field, magnetic field, electromagnetic wave, and seismic wave) reflected, radiated, or scattered by it, and carries out extraction, judgment, processing, analysis, and application.

This research uses the integration of ENVI software arc GIS software of remote sensing technology to analyze the problem. The integrated development of ENVI and ArcGIS has the characteristics of using ENVI as an image processing engine to solve the professional image processing process and the problems of data browsing, grid vector superposition, vector editing, rendering, thematic mapping and spatial analysis through arc GIS.

\subsection{Introduction of remote sensing image data}

Landsat - 5 is the fifth satellite in the American Landsat series, which was launched on March 1, 1984. Landsat - 5 has a design life of 3 years, but it has successfully operated in orbit for 29 years (officially declared invalid on June 5, 2013). it is currently the optical remote sensing satellite with the longest operating time in orbit and has become the most widely used and most effective remote sensing information source for earth resources satellites in the world.

Landsat - 8 was launched from the us land on February 11, 2013 and is equipped with an operational land imager (OLI) and a thermal infrared sensor (TIRS). Oli belongs to passive remote sensing, which can detect the solar short-wave radiation reflected from the earth's surface and the long wave radiation emitted from the earth's surface. among its nine bands, the 8th band is the full color band with a spatial resolution of $15 \mathrm{~m}$ and the other 8 bands have a spatial resolution of $30 \mathrm{~m}$, ranging from infrared to visible wavelengths. TIRS is used to collect the earth's heat in order to understand the water consumed in the observation area.

\section{Remote Sensing Image Data Processing}

This paper takes Daihai lake as the object of water quality monitoring. the monitoring time is September 1, 2008 and November 4, 2017. The image data conditions selected in this study are clear and cloudless over Daihai lake and high visibility. Therefore, synchronous satellite data that is close to the sampling time was found from USGS website, and a series of processing was carried out on it at the same time.

\subsection{Radiation calibration}

Radiometric calibration is the ground object information recorded in the original remote sensing image. it is expressed as gray value or brightness value, i.e. DN (digital number) value. radiometric calibration is the conversion of $\mathrm{DN}$ value recorded by the sensor into absolute radiance value. The radiation calibration can be done directly by ENVI software.

\subsection{Atmospheric correction}

Atmospheric correction is that when the sensor receives the reflection spectrum information of the ground object, due to the interference of atmospheric factors, there is not only ground object 
information but also more useless atmospheric information in the radiation information. in addition, the reflectivity of the water body itself is very low, which affects the remote sensing image. The process of atmospheric correction is to eliminate this kind of influence, thus obtaining real physical model parameters such as reflectivity, emissivity and surface temperature of ground objects. The software commonly used for atmospheric correction is envi software.

\subsection{Geometric correction}

Geometric correction is an original remote sensing image, which will be affected by external factors and appear certain geometric distortion, which includes systematic and non-systematic influences. The systematic influence of satellite is caused by the structure and performance of satellite sensors. The non-systematic influence is caused by the flight attitude, altitude, velocity, atmospheric refraction and terrain changes of satellite sensors. Therefore, the original image needs to be geometrically corrected. the principle is to use a mathematical model to create a corresponding relationship between the original image and the standard image, and to convert the pixel information of the image to be corrected into the standard image, thus realizing the correction of geometric distortion. In this paper, envi software is used to carry out geometric correction on remote sensing images.

Through radiation calibration, atmospheric correction and geometric correction, the pre-processing of remote sensing images is basically completed. Then, envi software is used to import the longitude and latitude of the sampling points into excel tables, extract the reflectivity of each sampling point, and finally obtain the reflectivity data of each sampling point in each wave band for later research.

\section{Data Processing}

Chlorophyll has a very high influence factor in the monitoring and evaluation of water environment. it can not only reflect the number of planktonic microorganisms in water body, but also reflect the degree of eutrophication in water body. Through remote sensing image processing in the early stage, a linear or logarithmic relationship model between remote sensing information and ground measured data is established.

From figure 1 and figure 2, judging from the spatial distribution characteristics, the chlorophyll concentration of Daihai lake was in a state of poor nutrition in large area in 2008. only the western region of the lake was in a state of severe eutrophication, while the eastern region was in a state of slight eutrophication. Compared with the 2008 chlorophyll remote sensing image, the chlorophyll concentration in 2017 increased overall, covering a large area, and was in a state of eutrophication. the chlorophyll concentration in the west of the lake decreased to a state of slight eutrophication.

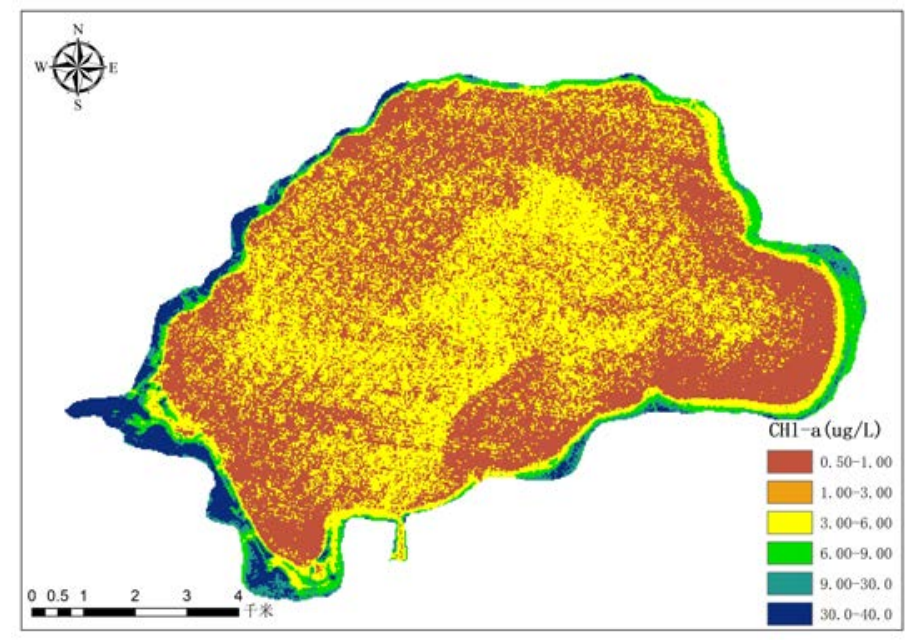

Figure 1 Chlorophyll remote sensing map of September 1, 2008 


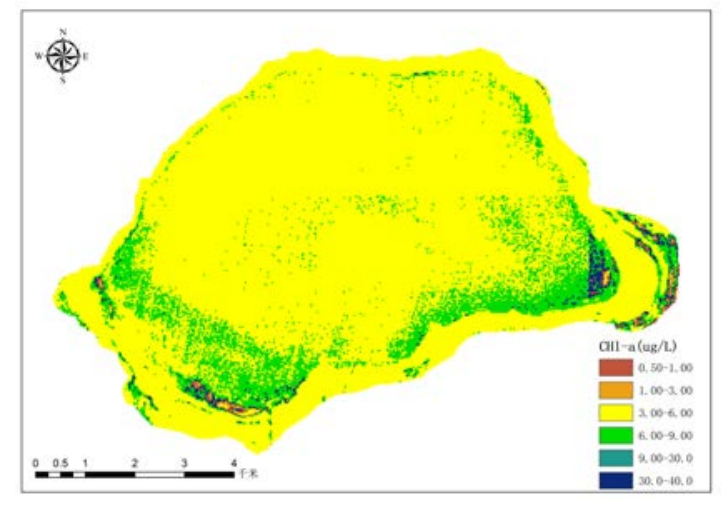

Figure 2 Chlorophyll Remote Sensing Map of November 4, 2017

The change of TP concentration in water body is also one of the important parameters to evaluate the nutritional status of water body. through the early remote sensing image processing, a linear or logarithmic relationship model between remote sensing information and ground measured data is established.

As can be seen from figure 3 and figure 4, from the spatial distribution characteristics, the large area of TP concentration in Daihai lake water in 2008 was $0.00-0.10 \mathrm{mg} / \mathrm{l}$, belonging to class ii water quality and in a state of poor nutrition. the TP concentration in the lake area was $0.16-0.35$ $\mathrm{mg} / \mathrm{l}$, in a state of moderate eutrophication, belonging to class iii and iv water quality. Compared with the 2008 TP remote sensing image, the TP concentration in 2017 increased to $0.10-0.12 \mathrm{mg} / \mathrm{l}$ in general, and the concentration in the lakeside area decreased, which was in a slightly eutrophic state and belonged to class ii water quality.

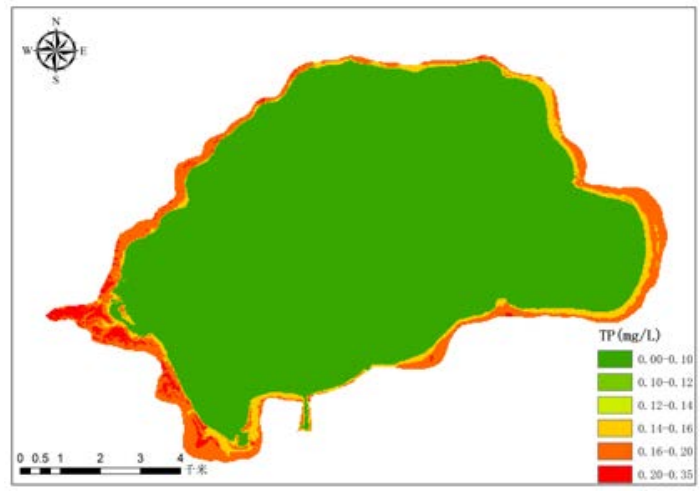

Figure 3 Total phosphorus remote sensing map on September 1, 2008

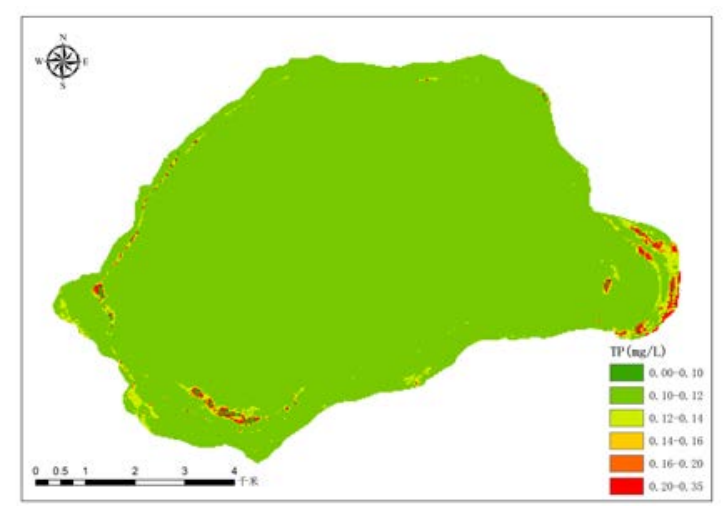

Figure 4 Total phosphorus remote sensing map on November 4, 2017

Analysis of Temporal and Spatial Distribution of Total Nitrogen. The change of TN concentration in water body is also one of the important parameters to evaluate the nutritional status of water body. through remote sensing image processing in the early stage, a linear or logarithmic relationship model between remote sensing information and ground measured data is established.

From figure 5 and figure 6 , judging from the spatial distribution characteristics, the large area of 
TN concentration in Daihai lake in 2008 was 0.9 - $1.2 \mathrm{mg} / \mathrm{l}$, which was in a eutrophic state and belonged to class iv water quality. the TN concentration in the lake area was $1.50-3.00 \mathrm{mg} / \mathrm{l}$, which was in a moderately eutrophic state and a severely eutrophic state and belonged to class iv and class $\mathrm{v}$ water quality. Comparing with the $2008 \mathrm{TN}$ remote sensing image, the TP concentration in the central area of Daihai lake water body basically remained unchanged in 2017. the moderate and severe eutrophic areas in the lake area increased and belonged to class $\mathrm{v}$ water quality.

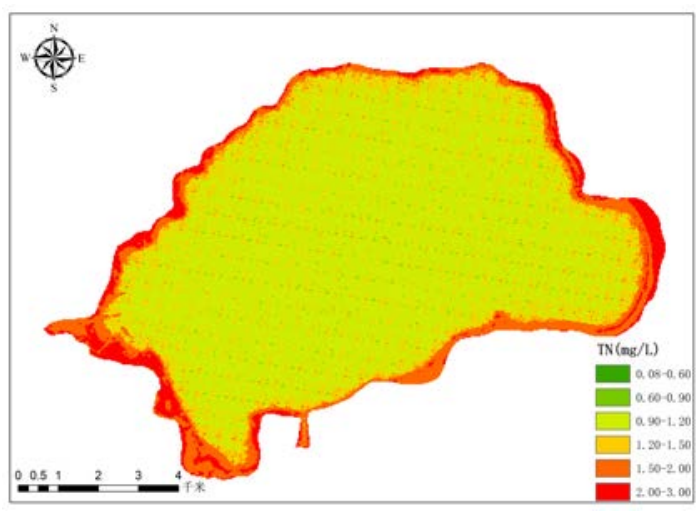

Figure 5 Total Nitrogen Remote Sensing Map of September 1, 2008

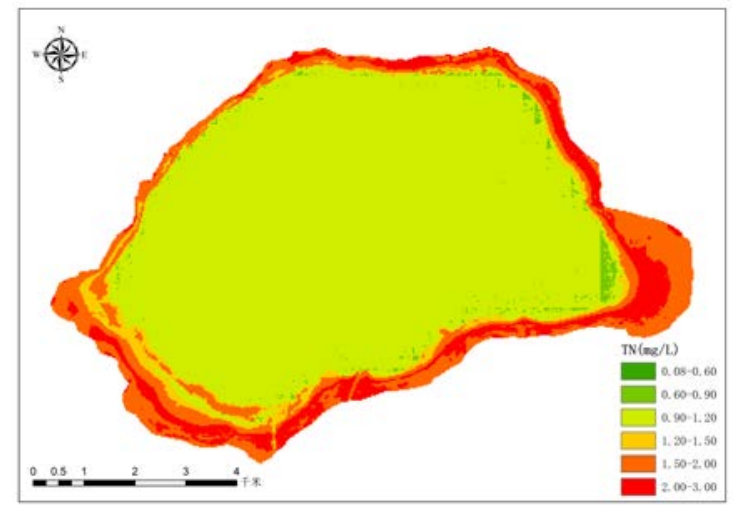

Figure 6 Total Nitrogen Remote Sensing Map on November 4, 2017

\section{Conclusion}

From the above, the remote sensing image shows that the overall concentrations of chlorophyll and total phosphorus in 2017 are higher than those in 2008, covering a large area. This shows that Daihai lake was eutrophic in 2017, the water quality was slightly salty, the total phosphorus exceeded 10 times, and the chlorophyll content was too high. On the contrary, the total nitrogen content decreased in periods and regions with high chlorophyll content.

The reason for this result is that with the change of TN and TP concentration from $0.08 \mu \mathrm{g} / 1$ to $1.2 \mu \mathrm{g} / 1$, the change of chlorophyll is small, i.e. the concentration of chlorophyll a is basically not affected by the change of TN and TP concentration. Chlorophyll content fluctuates up and down with the change of TN concentration. when TN concentration is between $2.0 \mu \mathrm{g} / 1$ and $3.0 \mu \mathrm{g} / 1$, chlorophyll content in water body decreases significantly with the increase of TN concentration, while when TN concentration is between $1.5 \mu \mathrm{g} / 1$ and $2.0 \mu \mathrm{g} / 1$, chlorophyll content increases significantly with the increase of TN concentration. Chlorophyll content increases exponentially with the increase of $t$ concentration, which indicates that the increase of total phosphorus in the water area will promote the increase of chlorophyll content in the water area. From the above data, we can see that although the eutrophication of Daihai lake in 2017 is not as serious as that in 2008, it still needs improvement. 


\section{Acknowledgements}

Fund Project: This research is one of the research results of the Natural Science General Project of Inner Mongolia Autonomous Region Scientific Research Project "Research on the Dynamic Changes of the Eco-environment in the Eastern Inner Mongolia Based on Remote Sensing and GIS Technology" (the project leader Wu Xiuqing, NJZY17236).

\section{References}

[1] Bian Fusheng, Fu Xiaofei, Ma Chao. Application Analysis of Remote Sensing Technology in Inland Water Quality Monitoring, Science and Technology Innovation Review, 2017(9):124-125.

[2] Cai Lina, Liu Pingbo, Zhi Changgui et al. Discussion on water quality remote sensing monitoring methods, mapping and spatial geography information [J], 2008 (8): 68-73.

[3] Liang Shunlin, translated by Fan Wenjie. Quantitative remote sensing [M]. Beijing: Science Press, 2009.

[4] Wang Lin, Bai Hongwei.Review of Research on Inversion of Lake Water Quality Parameters Based on Remote Sensing Technology, Global Positioning System [J], 2013(1):57-61+72. 